\title{
Variation in secondary structure of the 16S rRNA molecule in cyanobacteria with implications for phylogenetic analysis
}

\author{
Klára ŘehÁKovÁ ${ }^{1 *}$, Jeffrey R. Johansen ${ }^{2,3}$, Mary B. Bowen ${ }^{2}$, Michael P. Martin² \& \\ Christopher A. SHEIL ${ }^{2}$
}

\author{
${ }^{1}$ Center of Biology, Institute of Hydrobiology, Na Sádkách 7, České Budějovice 37005 and Institute of Botany, \\ ASCR, Dukelská, Třeboň, Czech Republic; *Corresponding authore-mail: krehakova@email.cz, phone 042- \\ $38-7775687$ \\ ${ }^{2}$ Department of Biology, John Carroll University, University Heights, OH 44118, USA \\ ${ }^{3}$ Department of Botany, Faculty of Science, University of South Bohemia, Branišovská 31, 37005 České \\ Budějovice, Czech Republic; e-mail: johansen@jcu.edu, phone 042-60-8305747
}

\begin{abstract}
The analysis of the phylogenetic signal in the sequence of the 16S rRNA gene in cyanobacteria and bacteria has been primarily limited to use of unweighted primary sequence in various cladistic analyses. Such analyses ignore the significance of secondary structure in the 16S rRNA molecule. Structure of this molecule is directly tied to its function, and consequently changes in primary sequence that lead to changes in the secondary structure theoretically have greater evolutionary significance than those changes that do not lead to structural changes. Very little analysis of the impact of primary sequence data on the secondary structure of the small subunit rRNA molecule in cyanobacteria has been reported. Herein is reported a secondary structure model of the full 16S rRNA sequence for Nostoc commune VAucher ex Bornet et Flahault. We also assess the variability in secondary structure of six variable helices in 180 OTUs of cyanobacteria. Variations were minor in most instances, and the observed motifs were not only similar among these cyanobacteria but also were similar to Escherichia coli, a well-studied, representative non-photosynthetic bacterium. Helix 17 was the most variable helix in terms of structure and length of primary sequence. In order to maintain the motifs, we assumed the presence of non-canonical base pairings in the helices. Phylogenies using primary sequence data alone and using primary sequence data in conjunction with coding for secondary structure were very similar, although secondary structural considerations produced trees that more closely reflected the current ultrastructure-based modern taxonomy in the group.
\end{abstract}

Key words: cyanobacteria, Microcoleus, Nostoc, Nostocales, Oscillatoriales, phylogeny, Pseudanabaenales, taxonomy, 16S rRNA secondary structure

Abbreviations: (CRW) Comparative RNA Website, (ITS) internal transcribed spacer, (OTU) operational taxonomic unit, (PCC) Pasteur Culture Collection

\section{INTRODUCTION}

Taxonomic relationships among prokaryotes often are difficult to determine as these organisms possess few morphological and physiological characteristics that can be used effectively in phylogenetic analyses. This limitation has been remedied in recent years through the use of DNA sequence data (e.g. TURNER 1997). Ribosomal RNA binds with numerous ribosomal proteins to form the ribosome, and the combination of conservative and variable regions in SSU rRNA have made sequence data of the SSU rRNA the gold standard of molecular phylogenetic analyses of prokaryotes since the molecule was first sequenced over 25 years ago (Brosius et al. 1978; CARBON et al. 1979).

Simple alignment of the $16 \mathrm{~S}$ rRNA primary sequence in isolation is less informative than analysis of that sequence constrained by secondary structure models (SMITH \& BOND 2003). The secondary structure of the 16S rRNA molecule is constrained by natural selection (Gutell et al. 2002), as functionality in this case is tied directly to various hierarchical levels of molecule structure (Fox \& WoESE 1975; Gutell et al. 1994). For example, variation in primary sequence is observed in helical regions, but the helical nature of the structure usually is not disrupted by this variation due to compensatory mutations that maintain similar base-pairing within the helix (MEARES et al. 2002). Recent work by SмIT et al. (2007) has shown that among prokaryotes, stem regions evolve faster than loops or bulges, suggesting that an initial mutation in a helix differentially biases selection for a compensatory 
mutation. In contrast, at least in some eukaryotic groups, the stem regions are the slowest to evolve (SMiTh \& Bond 2003).

Comparative analyses of 16S rRNA secondary structures have been completed for at least 232 bacteria, but only six of these structures are cyanobacteria (see the Comparative RNA website [CRW], CANNONE et al. 2002). The only published structure of a cyanobacterial 16S rRNA molecule is that for Chlorogloeopsis PCC7518 (WILMOTTE et al. 1993). Unpublished cyanobacterial 16S rRNA structures also exist for Anabaena PCC7120, Chlorogloeopsis PCC7518, Planktothrix rubescens (D.C. ex Gomont) AnAGN. et KomÁrek NIVA-CYA 18, Pleurocapsa PCC7516, Synechocystis PCC6803, and Synechococcus PCC6301 (CANNONE et al. 2002). Herein, we report the 16S rRNA structure for Nostoc commune VAUCHER ex BORNET et FLAHAUlt, and compare the structures of the most variable helices for numerous cyanobacterial taxa representing a wide diversity of genera and species in the Pseudanabaenales, Oscillatoriales, and Nostocales. The impacts of using secondary structure in phylogenetic analyses are also discussed.

\section{Materials ANd Methods}

Classification. Cyanobacterial diversity has been organized under a number of different classification schemes. We consider the newest proposals based on morphology, ultrastructure, and sequence-based phylogeny to be preferred (HoFFMANN et al. 2005), and we follow this taxonomic system throughout this paper. Classifications that combine all non-heterocytous filaments into a single order (e.g., the Oscillatoriales), or all coccoid cyanobacteria into a single order (e.g., Chroococcales) are in error based upon phylogenetic evidence (Hoffmann et al. 2005). We also reject the numbered subsection system used by some microbiologists (CASTEnHOLTZ 2001), as these define polyphyletic assemblages (e.g., Subsection I the Chroococcales and Subsection III the Oscillatoriales). This is a system of convenience that confuses systematic understanding.

Generation of Sequence Data. DNA was extracted using UltraClean Microbial DNA Isolation Kits (MO BIO Laboratories, Carlsbad, CA). The 16S rRNA gene was amplified in two separate PCR reactions. In the first reaction, a PCR product of $\sim 1600$ bps containing the $16 \mathrm{~S}-23 \mathrm{~S}$ ITS (from bp 359 in the 16S rRNA gene to bp 45 in the 23S rRNA gene) was generated using Primers 1 (Table 1; WiLmotte et al. 1993) and 2 (Table 1 and NüBEL et al. 1997). Reaction conditions, including primer sequences and temperature profiles, were identical to those reported in detail in FLECHTNER et al. (2002) and BOYER et al. (2002). In the second reaction, a PCR product was amplified from the ribosomal operon promoter (bp -181) to bp 378 of the 16S rRNA gene; 16S promoter and $16 \mathrm{~S}$ reverse primers were used in this reaction (Table 1). Standard conditions were used and included a 53 ${ }^{\circ} \mathrm{C}$ annealing temperature.

PCR products were analyzed on agarose gels before being purified from the reaction. Subsequently, $4 \mu \mathrm{l}$ of purified PCR product was TA-cloned using a TOPO-TA Cloning Kit (Invitrogen Corporation, Carlsbad, CA) according to instructions provided by the manufacturer. Automated sequencing of at least two clones from each PCR reaction was completed by either Cleveland Genomics or the Genomics Core Facility at Case Western Reserve University with Primer M13 Forward and M13 Reverse (plus Internal Primers 5, 7, 8; Table 1).

Sequence data were deposited in GenBank. Additional sequences for other taxa used in the phylogenetic analyses were obtained from GenBank (180 OTUs were used in the phylogeny and to determine secondary structures). GenBank accession numbers appear in Figures 8 and 9 for those strains not in large clades. All accession numbers and sources for sequence data can be found in the supplemental data for this paper (S1).

Forward and complementary sequences were aligned using the CLUSTAL W Multiple Sequence Alignment Program (Thompson et al. 1994). Ambiguities and PCR errors were checked manually and the chromatograms were used to make corrections where it was appropriate. Corrected sequences were aligned with sequences from GenBank as well as sequences from other strains that have been determined in the Johansen laboratory.

Determination of Secondary Structure. Secondary structures of the helices in cyanobacterial 16S rRNA molecules were determined by comparative analysis with published structures that were generated using covariation analysis with supporting evidence from high resolution crystal structures (e.g., Escherischia coli (Migula) Castell. et Chalm., Thermus thermophilus (Yoshida et Oshima) Oshima et IMAHORI) as reported on the Comparative RNA web site (CANNONE et al. 2002). In some instances, nucleotide changes in our sequences prevented formation of canonical base pairings. In these cases, alternative structures were explored by placing the helix sequence in Mfold 3.2 (ZUKER 2003) and determining possible thermodynamically-stable structures. Our structures are only hypothetical (not supported by crystallography), and we propose these structures using several guidelines: 1) we closed bilateral bulges (internal loops) that were in published models when G:C pairs could be formed contiguously to non-canonical pairing bases in the stem; 2) we did not maintain paired structure when multiple non-canonical base pairings were present in place of canonical (G:C, A:U) or wobble $(\mathrm{G}: \mathrm{U})$ base pairs; and 3 ) when two or more secondary structures have nearly identical thermodynamic stability, we report these as alternative structures.

The secondary structure for Nostoc commune WY1KK1 (a macroscopic terrestrial strain with typical morphology for the species from Wyoming, USA), as well as comparative secondary structures of six selected variable domains (for all 180 sequenced strains), were illustrated using Adobe Illustrator software. These variable domains are H15, H17, $\mathrm{H} 21, \mathrm{H} 22-23, \mathrm{H} 41$, and H44, which were named according to recently-published structures on the CRW site, which is managed by Robin Gutell (CANNONE et al. 2002). We also followed the symbol conventions of CRW for base pairings in which A:U and G:C canonical base pairs are connected by a thick dash $(-), \mathrm{G}: \mathrm{U}$ wobble bases by a small solid $\operatorname{dot}(\bullet)$, A:G wobble pair by a hollow dot $(\circ)$, and the considerably rarer non-canonical base pairings with a large solid dot $(\bullet)$. For those unfamiliar with terminology associated with secondary structure of RNA, examples of stems, terminal 
Table 1. Primers used to amplify the $16 \mathrm{~S}$ rRNA gene in cyanobacteria.

PCR 1: bp 359 to end of 16S rRNA gene:

Primer 1: 5'-CTCTGTGTGCCTAGGTATCC-3' (Wilmotte 1993). Reverse primer at bp 26-45 in 23S rRNA gene. Primer 2: 5'-GGGGAATTTTCCGCAATGGG-3' (NüBel et al. 1997). Forward primer at bp 359-378 in 16S rRNA gene.

Primer 3: 5'-CGCTCTACCAACTGAGCTA-3' (WiLmotTE 1994). Reverse primer in tRNA ${ }^{\text {ALA }}$ gene in the $16 \mathrm{~S}-23 \mathrm{~S}$ ITS. Used when Primer 1 failed to amplify.

Primer 5: 5'-TGTACACACCGCCCGTC-3' (Wilmotte 1993). Forward primer at bp 1391-1407 in the 16S rRNA gene (internal primer for sequencing PCR 1 product).

Primer 7: 5'-AATGGGATTAGATACCCCAGTAGTC-3' (NüBel et al. 1997). Forward primer at bp 781-805 in the 16S rRNA gene (internal primer for sequencing PCR 1 product).

Primer 8: 5'-AAGGAGGTGATCCAGCCACA-3' (adapted from WiLmotte 1993). Reverse primer at bp 1522-1543 (end) of 16S rRNA gene (internal primer for sequencing PCR 1 product).

PCR 2: Leader sequence of ribosomal operon, bp -181-378 of 16S rRNA gene:

16S promoter: 5'-GGATATATTGGATAAGTGCC-3' (Developed for this study, region from 182-163 bp upstream of the Anabaena variabilis ATCC29413 16S rRNA was chosen to amplify partial ribosomal leader sequence). Forward primer in leader sequence of ribosomal operon.

16S reverse: 5'-CCCATTGCGGAAAATTCCCC-3' (NüBEL et al. 1997). Reverse primer at bp 359-378 in 16S rRNA gene.

loops, and bilateral bulges are shown for Helix 41 (Fig. 1) as well as a key for the various types of pairings.

Phylogenetic Analyses. Phylogenetic analyses of the 180 strains for which comparative secondary structure was determined were completed using standard analyses (unweighted aligned sequence) as well as analyses using weighting for stems, gap analysis, and secondary structure motifs. The purpose of these analyses was to assess the impact of weighting and secondary structure motifs on analysis, and so only the criterion of parsimony was used since it can readily accommodate non-sequence data.

Sequence identity was compared among all strains and aligned visually. We used a partial 16S rRNA sequence from nucleotides 359-1490 (E. coli numbering) as this length was available in diverse genera of cyanobacteria. Phylogenetic trees were generated using PAUP* 4.02b (SWOFFORD 1998) to conduct heuristic searches (1000 replicates each) using parsimony with gaps equivalent to missing sequences, the TBR branch swapping algorithm, and steepest descent (SWOFFord 1998). Bootstrap analyses were run using heuristic searches with 1000 bootstrap replications (resamplings).

After the standard unweighted analysis was completed, additional analyses were run in which nucleotides paired in stems were downweighted (weight of 0.5) in comparison to unweighted nucleotides (weight of 1.0) in terminal and non-terminal loops. There are several inserts in the 16S rRNA gene in several taxa (e.g., Microcoleus vaginatus (VAUCher) Gomont, GARCiA-Pichel et al. 2001; BOYER et al. 2002). Sixteen nucleotide gaps associated with these synapomorphic inserts were coded as indels (scores: $1=$ gap; $0=$ inserted base). For the six variable helices we obtained 34 structural types in the 180 strains used in the analysis (H15:3; H17:9; H21:7; H22-23:3; H41:4; H44:8). For many sequences we were missing the last base pairs and thus could not determine the structure of $\mathrm{H} 44$ for these sequences. Consequently, only 26 patterns were coded (1 $=$ present; $0=$ not present). A weighting of 2 was given to these 26 binary characters because a change in secondary structure was considered to have greater weight than a single nucleotide change. In this analysis: 497 characters had a weight of $1.0 ; 605$ characters had a weight of 0.5 ; and 26 characters had a weight of 2.0. Of these, 391 characters were potentially parsimony-informative, including all of the 26 secondary structure characters.

\section{Results}

\section{Variation in Secondary Structure}

The secondary structure for Nostoc commune WY1KK1 (Fig. 1) was very similar to recently-published diagrams for the small subunit rRNA molecule in E. coli (Gutell et al. 2000; Elgavish et al. 2001). Differences were notable only in helices H10 (shorter helix), H15 (insert of four bases in terminal loopan autapomorphy unique to this strain), H17 (shorter helix), and H44 (several differences in subterminal region). $\mathrm{H} 39$ differed distinctly from $E$. coli in that the subterminal bilateral bulge was closed by the formation of a four base-pair helix rather than the two base-pair helix in E. coli (shaded boxes in upper right corner; Fig. 1). This helix was universal for all cyanobacteria included in this study, and this exact pairing was conserved in 176 of the 180 cyanobacterial sequences examined, therefore providing strong evidence that this structure occurs. In E. coli, a non-canonical G:A pair would yield the same structure if it occurred in place of the G:C pair present in the majority of cyanobacteria. Trichormus variabilis (KÜTz.) KoMÁreK et ANAGN. (AJ630456 and AJ630457) had the same sequence as in E. coli, providing further evidence that a G:A interaction forms at this position. This putative 


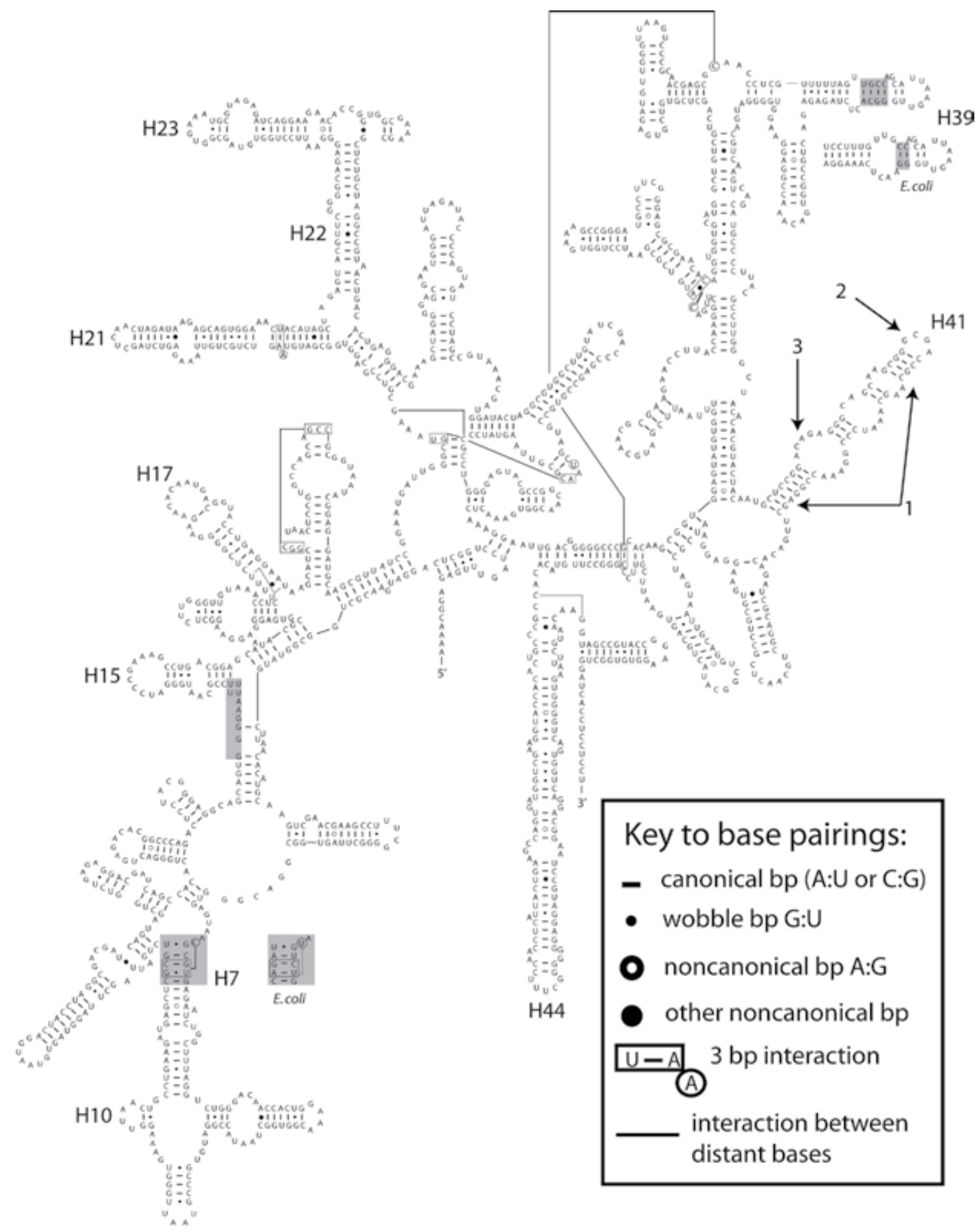

Fig. 1. Secondary structure of the small subunit (16S) rRNA molecule for Nostoc commune WY1-KK1. Two comparisons with E. coli not shown in other figures are shown for $\mathrm{H} 7$ and $\mathrm{H} 39$. Conventions for showing tertiary structure and non-canonical base pairing were adopted from the Comparative RNA Web Site (CANNONE et al. 2002). Structure definition is provided using numbered arrows for H41: (1) stem or helix, (2) terminal loop, (3) bilateral bulge. 


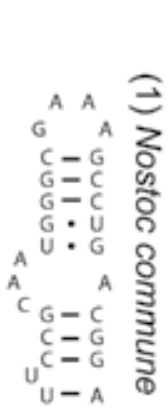

(a)

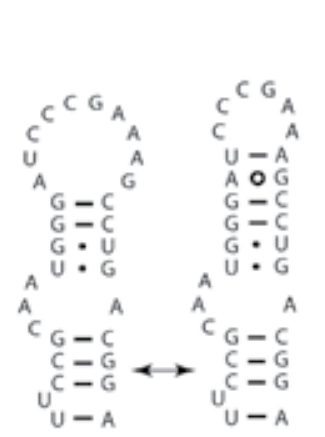

(b)

H15

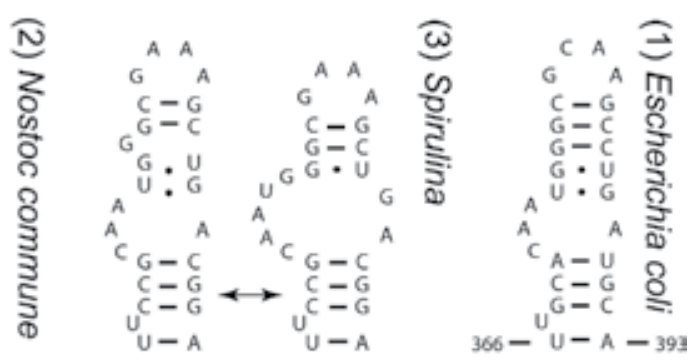

Fig. 2. Helix 15: (a) Nostoc commune NC1 showing type 1 structural motif (See Table 2 for explanation of structural motif); (b, c) Nostoc commune WY1-KK1 (type 2); (d, e) Spirulina PCC6313 (type 3); (f) Escherichia coli (type 1). Arrows indicate alternative stable structures. Detail on types given in Table 2 .

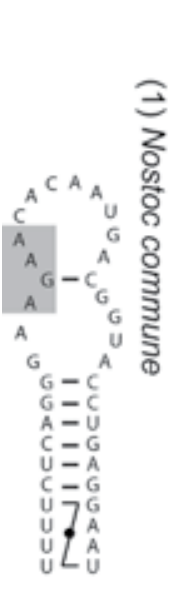

(a)

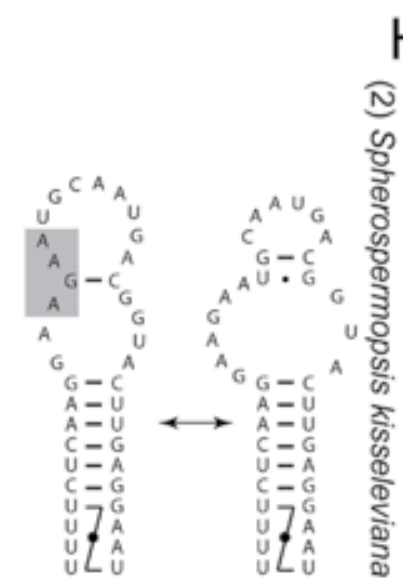

(b) (c) (f)

\section{$\mathrm{H} 17$}

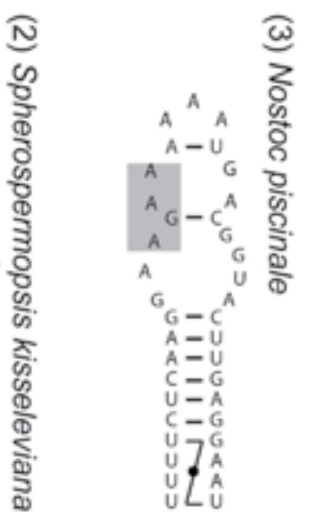

(d)

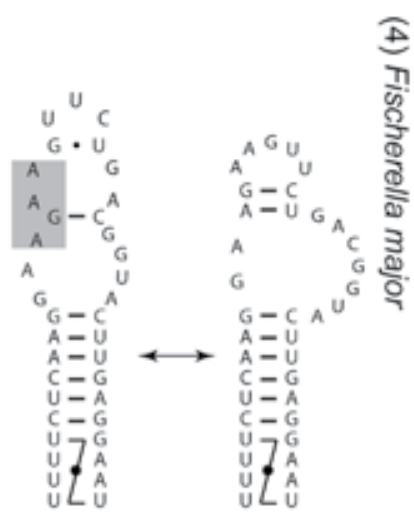

(e) (e) 
interaction in $E$. coli already has been hypothesized by others (CANNONE et al. 2002).

The tertiary interactions hypothesized for $E$. coli were all possible in Nostoc and other cyanobacteria examined by us (Gutell et al. 1994; CANnONE et al. 2002). These are noted by lines connecting distantlyseparated bases (Fig. 1). A synapomorphy shared by all 180 cyanobacterial OTUs was in the multibase structure in $\mathrm{H} 7$; in $\mathrm{E}$. coli the sequence for this multibase structure is completely different (Fig. 1, inset). In all cyanobacteria examined here (Chlorogloeopsis X68780, Anabaena X59559, Microcystis aeruginosa (Kütz.) Lemmerm. U03402, Synechococcus X03538, Synechocystis D64000, D90916, Nostoc commune WY1-KK1 EU586733), the exact sequence for this pairing was conserved.

The E. coli helix H10 exhibits 8 base-pairs and a 2-base bulge, whereas H10 in cyanobacteria consistently was very short, and defined by a helix of only two canonical base-pairs (Fig. 1). This short helix was conserved in all 180 cyanobacterial OTUs. The terminal loop varied in sequence, but was rich in $\mathrm{A}$ and $U$ in most strains.

A summary of the structure of the most variable helices is given in Table 2. Identical structural types are grouped by different numbers, with subscripts indicating differences in sequences due to compensatory base-pair changes that maintain the type. We illustrate and describe variation in these structural types below.

H15 was the least variable of the helices we examined. Most of the cyanobacteria had a helix that was conserved both in structure (Fig. 2a) and sequence $\left(1_{1}\right.$ in Table 2$)$. The type " 1 " structure is identical to the structure hypothesized for $E$. coli, although none of the cyanobacteria had the same sequence. Additionally, the H15 in Nostoc commune NC1 possessed a GNRA tetraloop and conservation of the G:G dinucleotide that has been shown to be footprinted by ribosomal protein S16 (Fig. 2a; PowERS \& Noller 1995). Nostoc commune WY1-KK1 had an autapomorphic 4-nucleotide insert in the terminus (Fig. 2b). It is possible that an $\mathrm{A}: \mathrm{G}$ base pair forms, thereby permitting closure of part of the terminal loop (Fig. 2c). Two cyanobacteria (Spirulina, Planktothrix) had a deletion in $\mathrm{H} 15$ that produced two different (but nearly equally-stable) structures (Figs $2 \mathrm{~d}$ and e). Of these two patterns, the first is most like that found in other bacteria (Fig. 2d), and therefore represents the most likely structure.

H17 was the most variable of all the helices examined, varying greatly in length and structure. However, the basal portion was highly conserved (Fig. $3)$. The terminus had a variable number of inserted bases (1-4, or 11 nucleotides). The most common type was an insert of 4 nucleotides that formed two loops at the terminus due to a single base pair in the center of the terminus (Fig. 3a). Many of the cyanobacteria had two thermodynamically-stable structures (Figs 3b, c, and $\mathrm{e}-\mathrm{j}$ ). Some of the taxa, including Nostoc piscinale and Fischerella major, varied through the formation of three consecutive loops at the terminus of the helix (data not shown). The structure in Gloeobacter was unique as two canonical base-pairs were present adjacent to the terminal loop (Fig. 3k). The 11 nucleotide insert in Microcoleus vaginatus produced an extended helix (Fig. $3 \mathrm{~m}$ ) that was closer to the $\mathrm{H} 17$ for E. coli than any other cyanobacterial taxon.

The consistent presence of an A:G below the $\mathrm{G}: \mathrm{C}$ or $\mathrm{U}: \mathrm{A}$ pairing in the terminus of $\mathrm{H} 17$ suggests an interaction is possible between these bases (Fig. 3). In particular, there was a highly conserved sequence (5'-AGAA-3'; Fig. 3, shaded boxes) that may be required for an interaction with ribosomal protein $\mathrm{S} 16$, an interaction shown with these four residues in E. coli (POWERS \& Noller 1995). An exception in primary sequence was the 5'-AUAA-3' sequence of Trichormus, which had a substitution of $\mathrm{A}$ for $\mathrm{C}$ to maintain the structural motif (Fig. 31). Only Gloeobacter lacked the structural motif (Fig. 3k).

H21 had five different structural types, but the majority were type " 1 " (Table 2; Figs 4a-f), which was very similar to the structure observed for E. coli. The difference between many of the cyanobacterial $\mathrm{H} 21$ and the E. coli $\mathrm{H} 21$ is that non-canonical base pairings in the basal part of the helix are necessary if the structure is to be conserved. We recognized 3 subtypes of the pattern $\left(1,1^{\prime}, 1^{\prime \prime}\right)$ based on the presence of an A:A, U:G, or A:C pairing. The Fischerellaceae forms all had the same subtype (1'; Table 2$)$, and so it seems possible that the alternative structure forms in at least some instances. In Nostoc commune HHCP (Fig. $4 \mathrm{i}$, we question the closure of the base as two A:A non-canonical base-pairs would be required to form on either side of a U:A pair, a thermodynamicallyweak configuration. Leptolyngbya appalachiana J.R. Johansen et C.E. Olsen (Fig. 4j) had a unique structure due to a deletion of 12-14 nucleotides near the terminus. We also did not include multiple non-canonical base-pairs in the subterminus of Microcoleus vaginatus (Fig. 4g) or Nostoc desertorum K. ŘehÁKová et J.R. Johansen (Fig. 4h) because these configurations would be unstable. We recognize that weak interactions may occur here that would convert the structures to the common type " 1 ". A three-base interaction reported in E. coli (CRW; CANNONE et al. 2002) appeared to be present in cyanobacteria as well (A-A:U; Fig. 4), although the bases were different in Mastigocladus laminosus COHN ex KIRCHNER (G-U:U; Fig. 4c). If this structure does not form, many of the taxa have an alternative stable structure (Figs $4 \mathrm{~b}$ and d). We favor the E. coli-like structure as Powers \& NOLLER (1995) have shown that ribosomal protein S8 interacts in this region. Powers \& Noller (1995) also noted that protein S16 has been shown to interact with the terminal loop and subterminal bulge.

$\mathrm{H} 22-\mathrm{H} 23$ showed great variation in sequence, 
but was conservative in structure. This helix is considered to be in the highly-conserved core of the ribosome (Meares et al. 2002), and part of the "minimal ribosome" necessary for ribosomal function across all phyla. The majority of strains had a structure nearly identical to that reported for E. coli (type "1"; Figs $5 \mathrm{a}-\mathrm{h}$ ). The major variability in this structure was observed in $\mathrm{H} 22$ (the basal part of H22-H23). The non-canonical A:G base pair present in E. coli was conserved in the non-heterocytous taxa (Figs $5 \mathrm{f}-\mathrm{h}, \mathrm{j}, \mathrm{k})$, but replaced by the more stable $\mathrm{C}: \mathrm{G}$ pair in all heterocytous taxa (Figs 5a-e, i). In order to maintain the typical structure of $\mathrm{H} 22$, it is necessary to assume the existence of additional non-canonical pairings in some of the taxa $(\mathrm{G}: \mathrm{A}$ in Aphanizomenon flos-aquae (L.) RALFs ex Bornet et FlahAult; U:C in Nostoc commune and Fischerella muscicola (THUR.) Gomont; Figs 5a, e, and i). The most distinctive difference occurred in the unilateral bulge near the base of $\mathrm{H} 22$, in which the A or G was replaced with a $U$ residue (Figs $5 i$ and $j$ ). This change characterized both type " 2 " and " 3 " structural motifs (Table 2). In some of the coccoid and pseudanabaenacean taxa (e.g., Spirulina and Cyanobium), a 2 nucleotide deletion led to shortening of $\mathrm{H} 22$ and a different structure in the loop at the junction of $\mathrm{H} 22$ and H23 (Fig. 5k). H23 had two alternative stable structures in Dolichospermum planctonicum (BRUNNTH.) WACKLIN et al. (Figs 5c and $d)$. These structures were dependent on whether two consecutive base pairs form in the bilateral bulge below the terminus. Slippage in pairing could result in reduction of the size of the bulge with a concomitant increase in the size of the terminal loop.

Although H41 showed considerable sequence variation, only four different types were found (Fig. 6, Table 2). The common motifs (type " 1 " and " 2 ") had a helix of 4 base pairs below the terminus, compared to the 3 base pair helix in E. coli, Planktothrix, and Microcoleus autumnalis (R. TREVIS. ex GomOnT) StruneckÝ, KomÁrek et JohANSEN (Figs 6e, g, h). Additionally, there was variation in the number of base pairs observed in the terminal end of the middle bilateral bulge. Types " 1 " and " 3 " had 2 base-pairs, whereas types " 2 " and " 4 " possessed 3 base-pairs. Other minor changes included additional base-pairings that reduced the size of the middle bilateral bulge. However, each structure exhibited the same length of basal helix and bilateral bulge size, regardless of motif.

For many of our taxa, H44 was not sequenced, so we report only a limited number of strains (Table 2). Interestingly, $\mathrm{H} 44$ was highly variable and showed a total of eight different structural motifs (Fig. 7), even though we had many fewer sequences available for comparison. These motifs varied primarily in the position and size of the bilateral bulges. It is interesting to note that the Fischerellaceae genera again had a distinctive structure (type "5", Fig. 7e).
Impact of Secondary Structure Analysis on Phylogenetic Analysis

One intention of this research was to determine if phylogenetic signal was apparent in the secondary structure of the small subunit rRNA molecule. Phylogenetic analyses that did not adjust for secondary structure (Fig. 8) yielded topologies that were very similar to those that included information about secondary structure (Fig. 9), however, bootstrap support usually was lower in analyses that included information from secondary structure. Despite these lower bootstrap values, secondary structure coding did seem to create more discrete large clades, particularly in the base of the tree. For example, in the analysis not using secondary structure, the Oscillatoriales (Fig. 8, Group III) did not form a monophyletic group, but rather formed two clades, one of which was sister to the Pseudanabaenales Group IV clade containing Spirulina and Geitlerinema. In this same analysis, there were six clades in Group IV (Synechococcophycidae) that form a grade between the Oscillatoriales (Oscillatoriophycidae) and Gloeobacter (Gloeobacterophycidae).

On the other hand, the tree that was constructed considering secondary structure (Fig. 9) resolved the Oscillatoriales (Group III) into a single monophyletic lineage. Microcoleus steenstupii J.B. Petersen (Group II) was more consolidated in the second analysis due to the fact that the Blennothrix couplet fell outside of the species clade (Fig. 9) instead of within it (Fig. 8). Two taxa (Microcoleus EU586738 and Microcoleus EU586739) were paraphyletic to Group II in the first analysis (Fig. 8), but were resolved as being in Group III in the analysis incorporating secondary structure data (Fig. 9). With the addition of the secondary structure data, four of the Group IV clades coalesced into a single clade (Fig. 9). The heterocytous taxa (Group I) exhibited similar internal topologies and monophyly of this group received relatively high bootstrap support in each analysis (Figs 8, 9). In the first tree, the Microchaetaceae are nested within the Nostocaceae (Fig. 8), whereas in the tree coded for secondary structure (Fig. 9) they formed a separate clade at the base of the heterocytous taxa. Thus on several fronts, the analysis utilizing secondary structure was more consistent with the modern higher level taxonomy of the cyanobacteria than the analysis utilizing sequence data alone.

\section{Discussion}

Information gathered from secondary structure of RNA molecules already has begun to play a role in cyanobacterial systematics and taxonomy. The secondary structure of the $16 \mathrm{~S}-23 \mathrm{~S}$ ITS molecule has been especially helpful in defining both genera 


\section{$\mathrm{H} 21$}

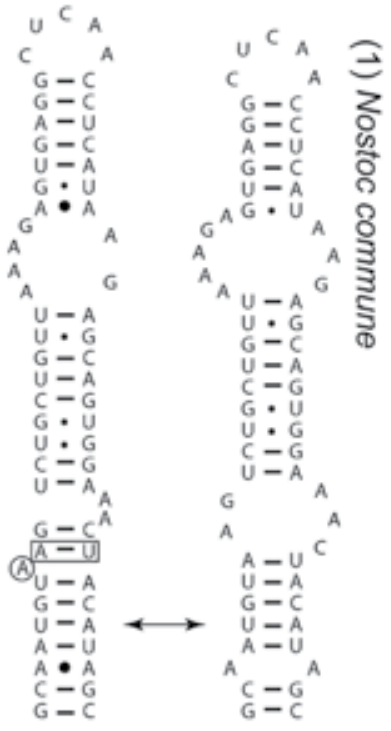

(a)

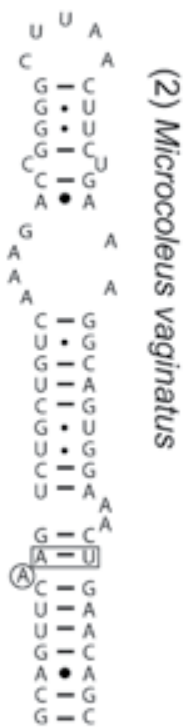

(g) (b)

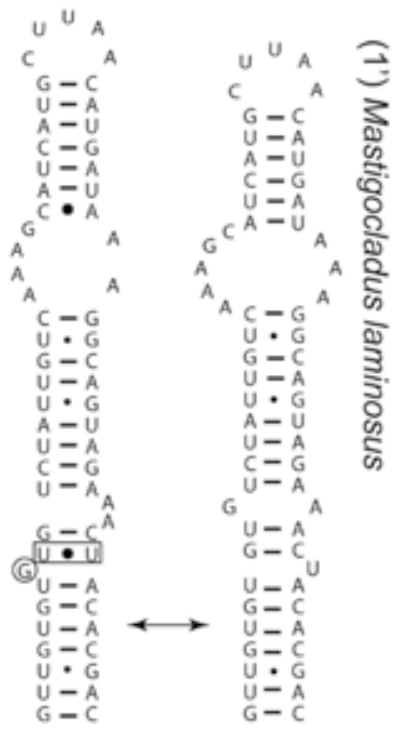

(c)

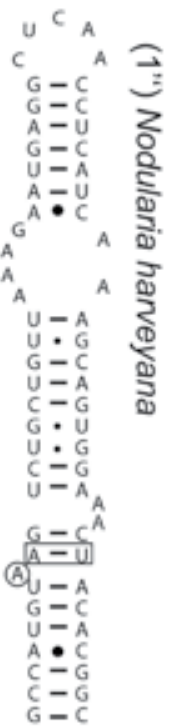

(e)

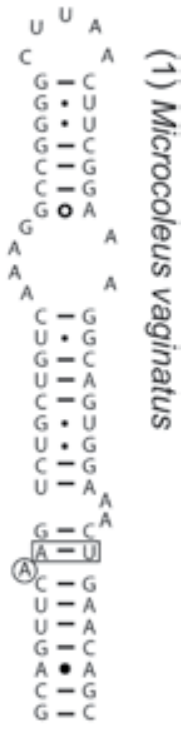

(f) (d)

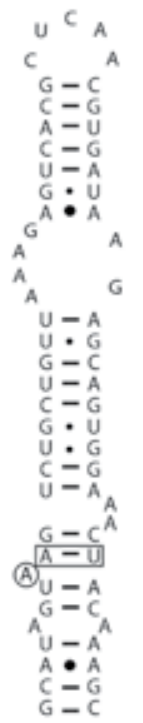

(i)

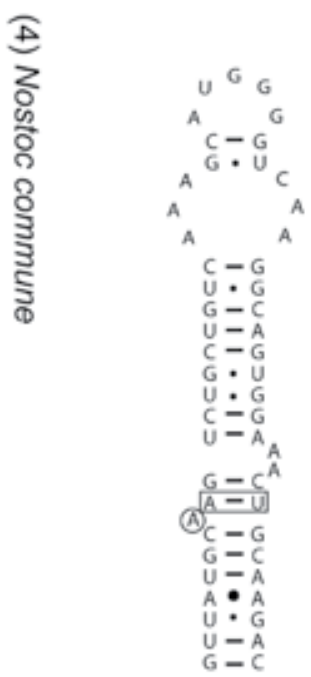

(j)

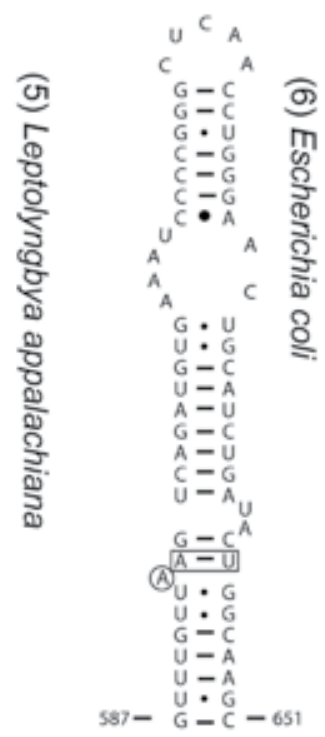

(k)

Fig. 4. Helix 21: (a, b) Nostoc commune NC1 showing type 1 structural motif; (c, d) Mastigocladus laminosus KOV1987 (type 1'); (e) Nodularia harveyana BECID29 (type 1"); (f) Microcoleus vaginatus CSV-MC1 (type 1); (g) Microcoleus vaginatus SEV2-MC1 (type 2); (h) Nostoc desertorum CM1-VF14 (type 3); (i) Nostoc commune HHCP (type 4); (j) Leptolyngbya appalachiana GSM-SFF-MF60 (type 5). Arrows indicate alternative stable structures. Detail on types given in Table 2.

and species (CASAmatta et al. 2006; ŘehÁKovÁ et al. 2007; Johansen et al. 2008, 2014; Siegesmund et al. 2008; LuKeŠOvÁ et al. 2009; BOHUNICKÁ et al. 2011; Perkerson et al. 2011; VAcCArino \& Johansen 2011; HAŠLER et al. 2012; JoHANSEN et al. 2014; HAŠLER et al. 2014; MühlsteinovÁ et al. 2014a, 2014b; OsorioSANTos et al. 2014). The present work examines the systematic signal in the secondary structure of the $16 \mathrm{~S}$ rRNA molecule, which is far less variable than the associated ITS region.
Undeniably, secondary structure of the $16 \mathrm{~S}$ rRNA molecule is critical for its function in the ribosome. The structure is under tight constraint by natural selection, and this has led to the molecule being highly conserved in its primary structure, and even more highly conserved in its secondary structure. Changes in the sequence can only persist in a lineage when those changes do not lead to a change in secondary structure, or when compensatory changes occur that restore secondary structure. In the rare instances 
(1) Nostoc commune

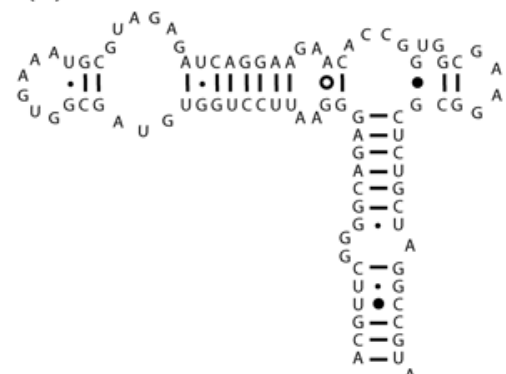

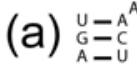

(c)

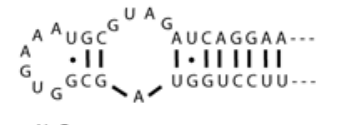

(d)

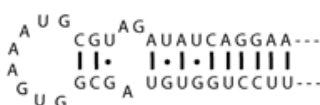

(1) Dolichospermum planktonicum

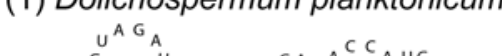

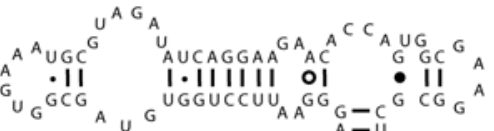

(1) Aphanizomenon flos-aquae

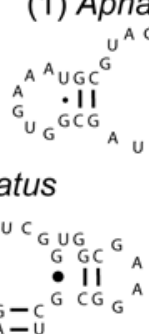

(1) Geitlerinema sp.

(1) Microcoleus vaginatus

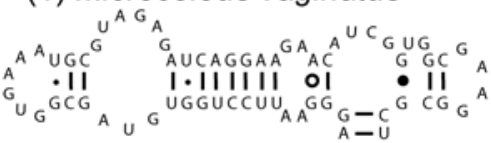

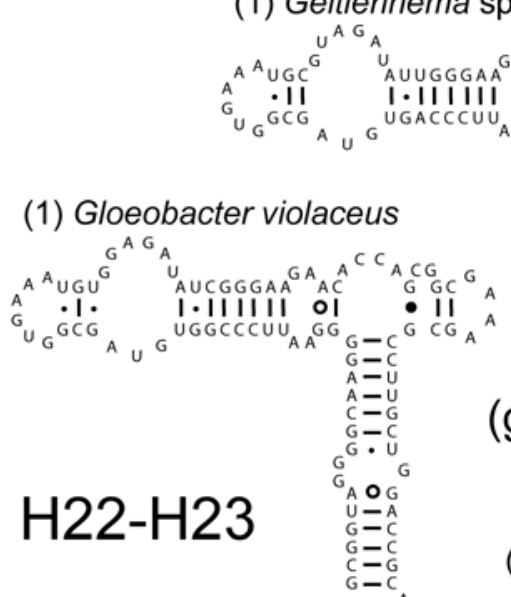

${ }_{A A} C^{C C} C_{G G G G}{ }_{G}{ }^{G}$
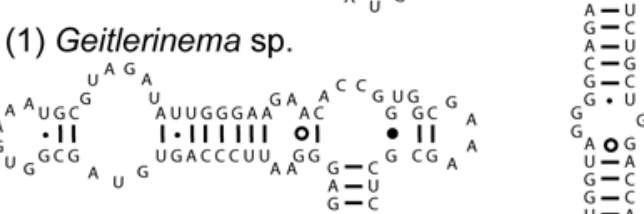

\section{(f)

$$
\begin{aligned}
& A=U \\
& U=A^{A} \\
& G=C \\
& A=C
\end{aligned}
$$$$
\text { (e) }{ }^{U}{ }^{U}=_{A}^{A} C^{A}
$$

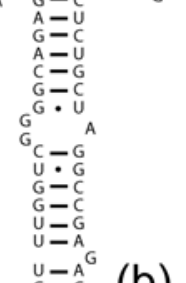

(2) Fischerella muscicola

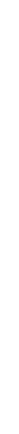

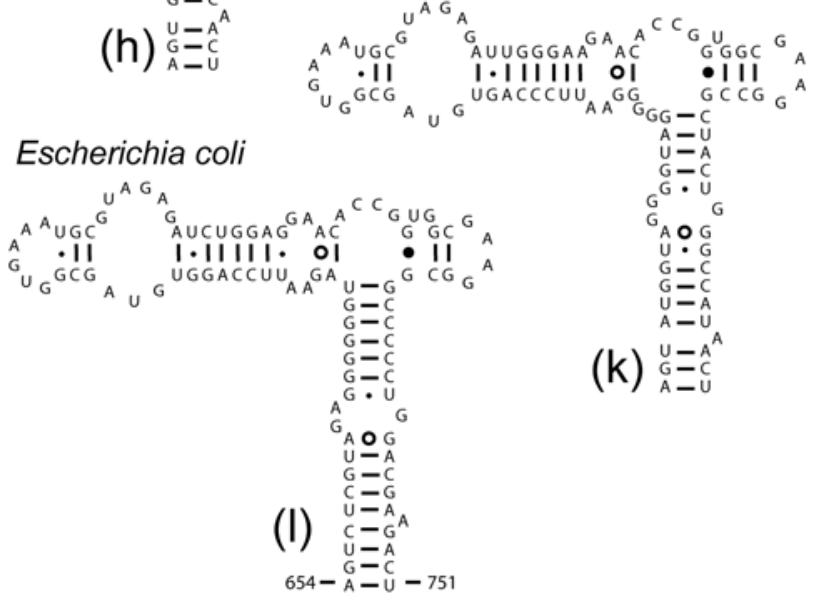

(2) Leptolyngbya boryana

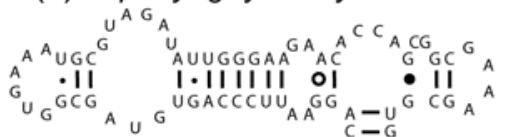

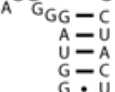

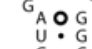

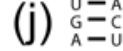

(3) Spirulina sp.

(g) ${ }_{A}^{G}=c^{G}=c^{A}$

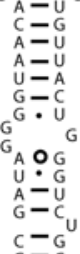




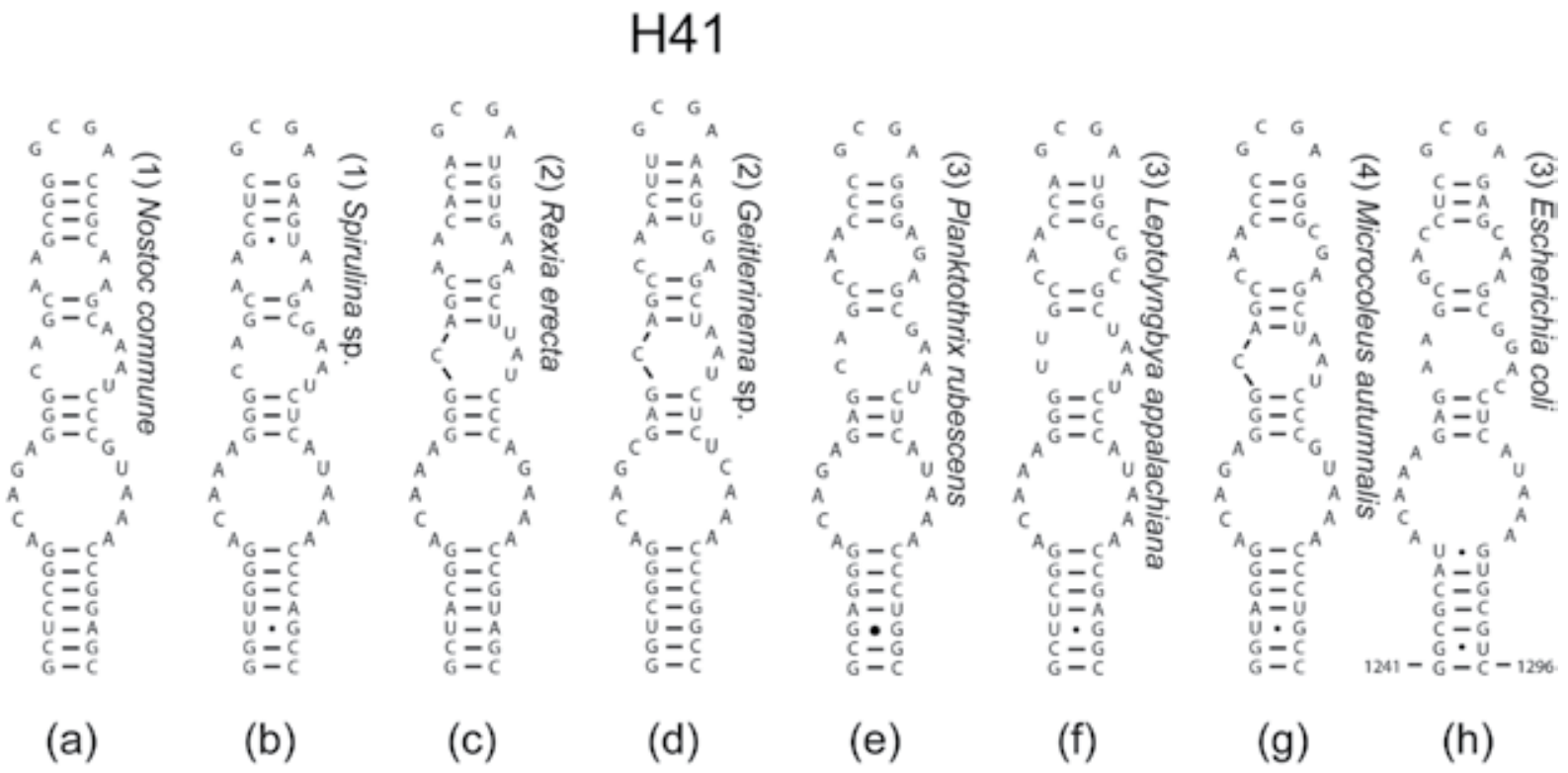

Fig. 6. Helix 41: (a) Nostoc commune NC1 showing type 1 structural motif; (b) Spirulina PCC6313 (type 1); (c) Rexia erecta CAT1-M (type 2); (d) Geitlerinema MBIC100006 (type 2); (e) Planktothrix rubescens NIVA-CYA227/1 (type 3); (f) Leptolyngbya appalachiana GSM-SFFMF60 (type 3); (g) Microcoleus autumnalis ARCT-PH5 (type 4). Detail on types given in Table 2.

\& Anagnostidis 1998, 2005; Hoffmann et al. 2005; KомÁReK 2013) and was less prone to production of basal clines within the tree. It is more consistent with a phylogeny derived from 31 protein sequences (SHiH et al. 2013) in that the large clade containing Cyanobium, Nodosilinea, Trichocoleus, and others is monophyletic. This is also consistent with a large phylogeny of Synechococcophycidae in Osorio-SANTOS et al. (2014, see Suppl. fig. 1). The monophyly of the Oscillatoriales (Group III) in Fig. 9 is also more consistent with other phylogenies than the separate clades shown in Fig. 8 (STRUNECKÝ et al. 2013). It is theoretically problematic that typical distance and maximum likelihood analyses remove information from gaps (scoring them as missing), as large gaps or inserts within these genes certainly alter secondary structure and may possess more phylogenetic information than the sequence data itself. H17, with its highly variable number of bases in the terminus, is likely one of the most phylogenetically-informative regions in the small subunit rRNA molecule, and yet usually it is simply coded as an unweighted sequence in most analyses.

With the variable inserts, it is apparent that the H17 terminus was formed not by single basepair substitutions or by single base-pair insertions and deletions, but rather, segments of many base pairs likely were inserted on the terminus in solitary (but evolutionarily significant) events. Alignment and analyses of primary sequence by phylogenetic software loses this critical signal. With the analysis of secondary structure it will be possible to code for these significant events, as was done here (Fig. 9). Though it did not lead to a markedly different tree, the theoretical improvement to the analysis is intuitive.
Phylogenetic signal also was apparent through comparative examination of some of the structures. The clearest such signal appeared in the highly variable H17, particularly with regard to the 11 base-pair insert in M. vaginatus (Fig. $3 \mathrm{~m}$ ). The Fischerellaceae also exhibited distinctive patterns, with H17-type 6 and H21-type 1' found only in that clade (Table 2). Some patterns were consistent even on the level of phyla (H7, H39 - see Fig. 1 and above text). However, the pattern with secondary structure in most cases was not clearly informative. Often the change of just one or two nucleotides leads to differences in structure, and identical structural types appeared (apparently independently) in separate clades. For example, H17-type 3 was present in Cyanobium (Synechococcophycidae), Planktothrix (Oscillatoriophycidae), and several heterocytous clades (Nostocophycidae) (Table 2). Since these taxa are very distantly related, and the majority of taxa have H17type 1, we conclude that this structure is analogous, not homologous, in these diverse strains. Some taxa did show striking internal consistency among several structural motifs, and this is clear evidence that at times the structural motifs are homologous. Microcoleus vaginatus is the best example of this latter consistency in pattern. Among the 23 strains of this species, all had H15-type 1, H17-type 9, and H41-type 4. The subgroup within the species that had H21-type 2 (instead of H21-type 1) may represent a separate lineage (Table 2). BOYER et al. (2002) postulated that $M$. vaginatus as currently recognized may contain cryptic species, and if these differences in secondary structure were congruent with at least some phenotypic traits an argument might be made to taxonomically recognize some of that diversity. 


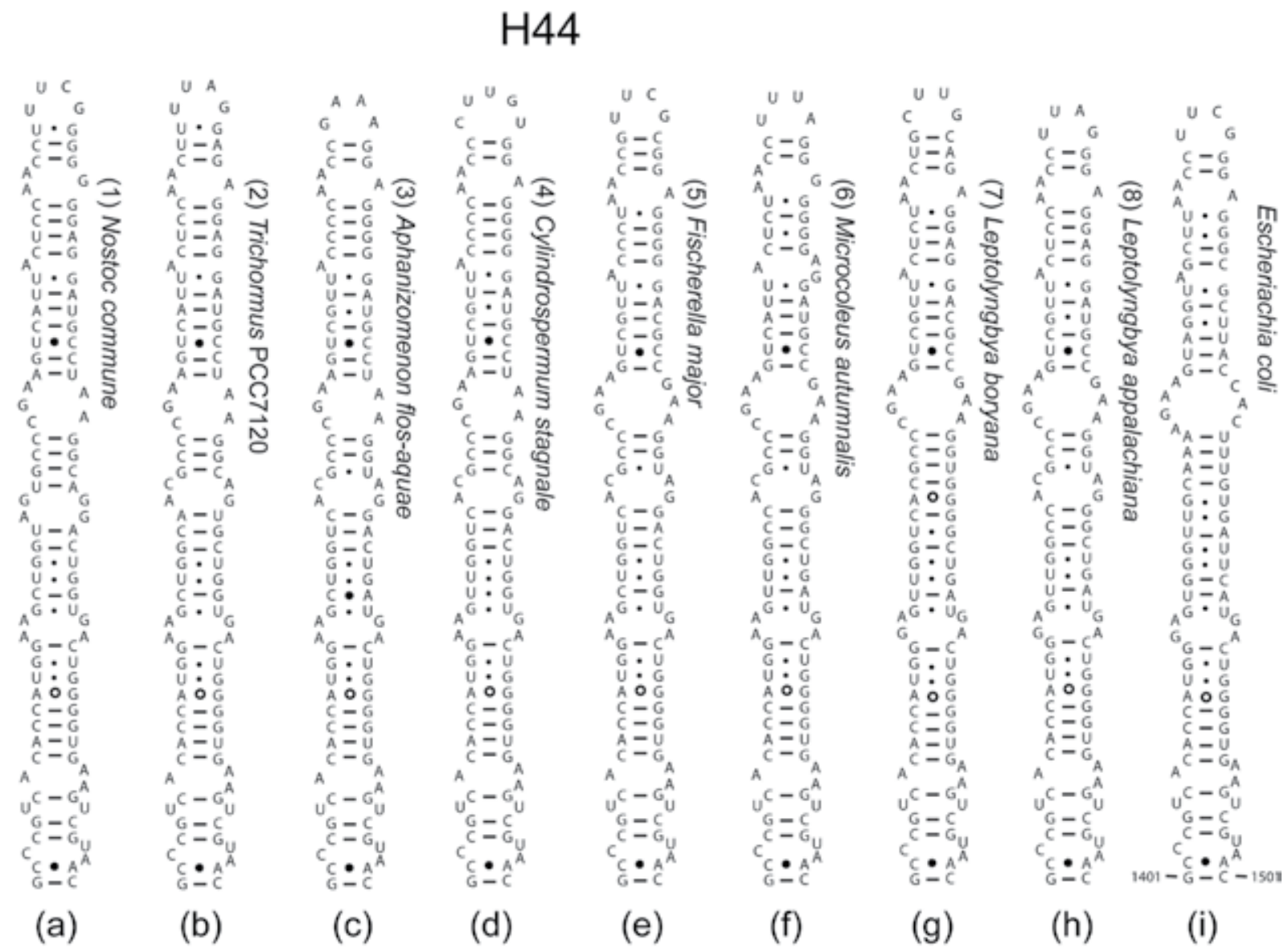

Fig. 7. Helix 44: (a) Nostoc commune NC1 showing type 1 structural motif; (b) Nostocaceae PCC7120 (type 2); (c) Aphanizomenon flos-aquae PCC7905 (type 3); (d) Cylindrospermum stagnale PCC7417 (type 4); (e) Fischerella major NIES592 (type 5); (f) Microcoleus autumnalis ARCT-PH5 (type 6); (g) Leptolyngbya boryana UTEX485 (type 7); (h) Leptolyngbya appalachiana GSM-SFF-MF60 (type 8). Detail on types given in Table 2 .

It is possible that with greater taxon sampling in the non-heterocytous taxa clearer patterns will emerge (GoERTZEN \& THERIOT 2003). The initial focus of this study was the Nostocales, and we expanded the study to other groups to see how much variance in structure might be present in the phylum. We recognize that sampling more taxa in both the Oscillatoriophycidae and the Synechococcophycidae may yield new and interesting structures. Nonheterocytous filaments have a more problematic taxonomy, as a few generic names (e.g. Phormidium and Oscillatoria) have been used fairly broadly in culture collections around the world. The present analysis suggests secondary structure of the $16 \mathrm{~S}$ rRNA molecule may have phylogenetic signal, but our trees do not demonstrate clearly that it does. Further experimentation with coding the structures for phylogenetic analysis is needed.

Secondary structure has been used by others to improve sequence alignment by identifying homologous positions (KJER 1995; GOTTSCHLING et al. 2001; Goertzen et al. 2003). We have found this critical in alignments of cyanobacterial 16S-23S ITS regions (PERKERSON et al. 2011; JoHANSEN et al. 2014; Osorio-SAntos et al. 2014). However, the 16S rRNA genes generally align well in cyanobacteria, except for a few regions (particularly H17 and H44). While this application will not likely make a large change in the phylogenetic analysis due to the small number of ambiguous positions, it is still an excellent way to obtain more accurate alignments.

Awareness of secondary structure also is critical for detecting potential sequence error. It is apparent from our comparisons of secondary structure of the small subunit rRNA molecule that this structure is remarkably conservative, a conclusion consistent with observations based on the other large datasets (GUTELL et al. 2002). We have focused on the variable regions, which differ only slightly. However, the majority of the molecule (not discussed in this paper) is very conserved in its structure (CANNONE et al. 2002). If sequences are double-checked by examining secondary structure, sequencing errors are much more likely to be detected, leading to more accurate reporting in sequence data. Whereas programs exist for evaluating likelihood of sequence error, such as Phred (EwING \& GREEN 1998; EwING et al. 1998), these programs do not provide a means for discriminating between ambiguities when such error is detected, and we have already found 


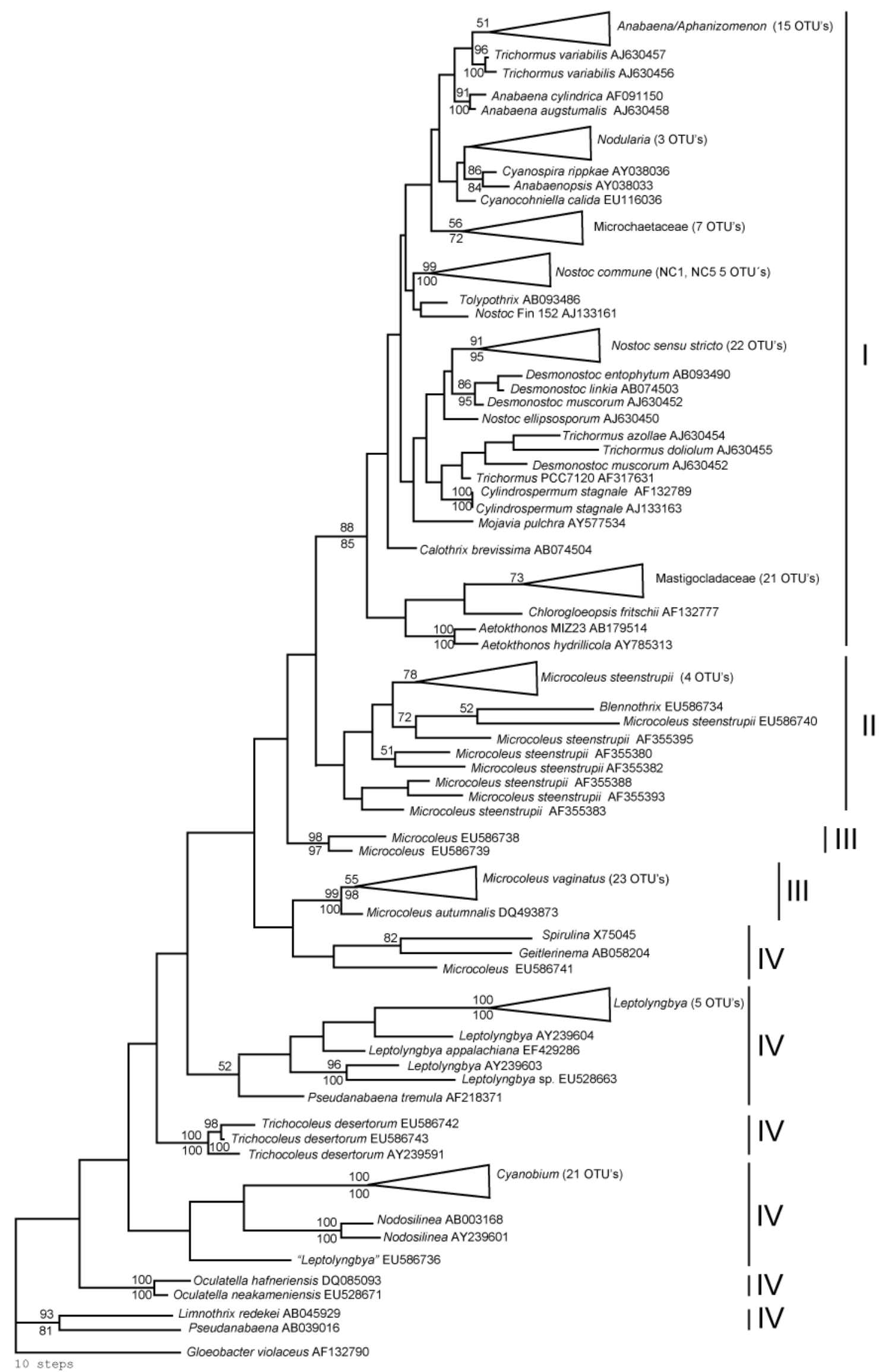

Fig. 8. Most parsimonious phylogenetic tree of 180 cyanobacterial taxa using unweighted sequence data. Bootstrap values only reported when above $50 \%$, above the line from parsimony analysis, below the line from distance analysis. Groups are: (I) Nostocophycideae (taxa with heterocytes); (II) Oscillatoriophycideae, Phormidiaceae (taxa with radial thylakoids); (III) Oscillatoriophycideae, Oscillatoriaceae (taxa with irregular thylakoids); (IV) Synechococcophycideae (taxa with parietal thylakoids). 


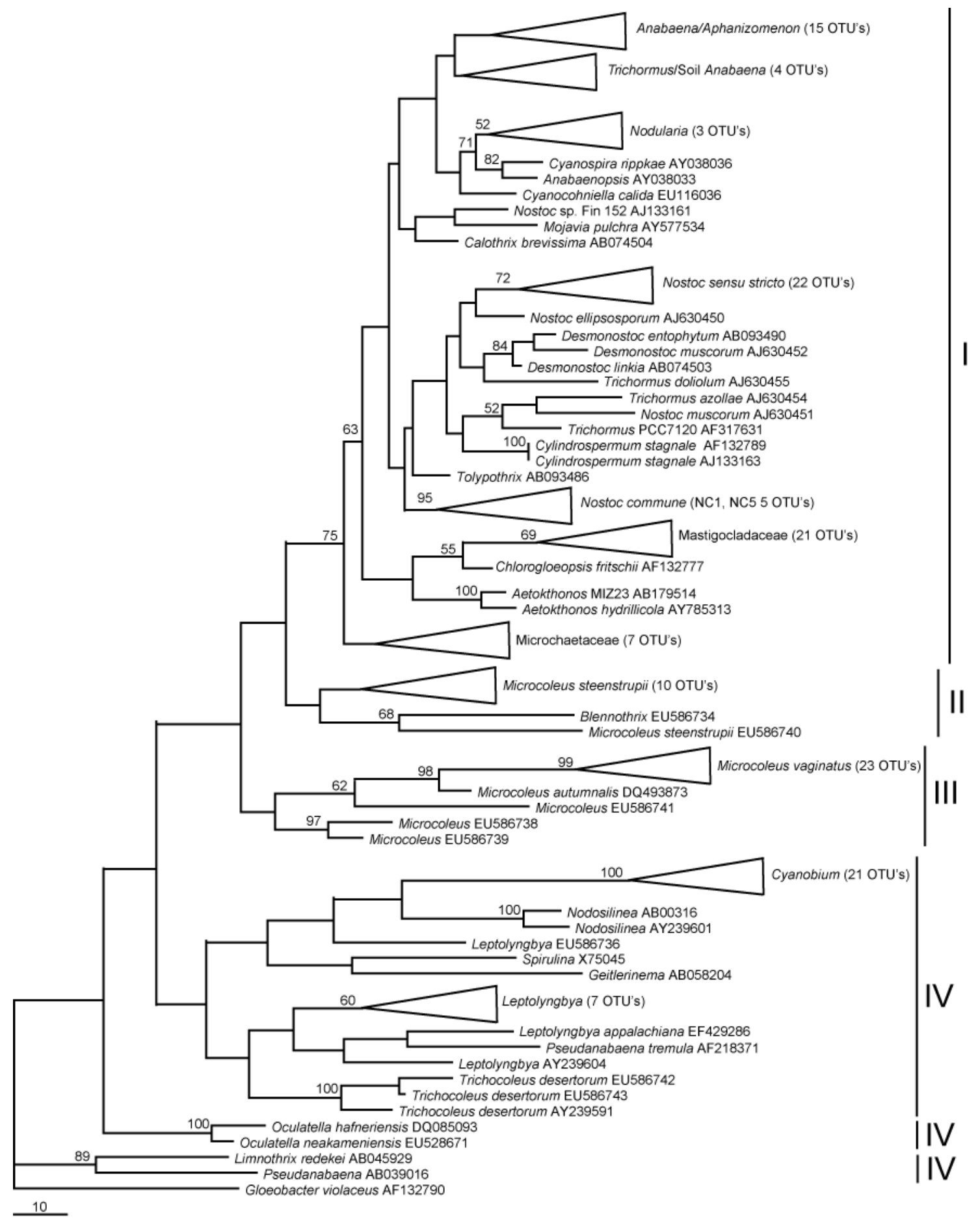

Fig. 9. Most parsimonious phylogenetic tree of 180 cyanobacterial taxa using sequence data weighted for secondary structure, with coding for gaps and secondary structure motifs. Bootstrap values from parsimony analysis only reported when above 50\%. Groups are: (I) Nostocophycideae (taxa with heterocytes); (II) Oscillatoriophycideae, Phormidiaceae (taxa with radial thylakoids); (III) Oscillatoriophycideae, Oscillatoriaceae (taxa with irregular thylakoids); (IV) Synechococcophycideae (taxa with parietal thylakoids).

this means of proofing sequences useful in our own work. This means of identifying potential sequence error is especially valuable for researchers obtaining sequences from national and international databases (e.g., GenBank), where Phred scores and the original chromatograms are not available to the researcher. Sequences producing deviant structures are suspect and should receive further evaluation before use in phylogenetic analyses.

The existence of non-canonical base pairs, widely accepted as occurring in a number of prokaryotic rRNA molecule secondary structures, causes problems in secondary structure determination (Gutell et al. 2002). Therefore, it is not always easy 
Table 2. Patterns of structure in variable loops in representative taxa (taxa with patterns identical to one of these representatives are not shown). Helices with the same structural motifs share the same number, with different subscripts denoting different sequences. Those helices with the same number and same subscript share identical sequence. Structures with the same number, but prime designation (e.g. 1, 1', $\left.1^{\prime \prime}\right)$ have the same structure only if non-canonical base pairs are assumed to form. Helix 44 is missing for those strains for which the sequence ends before the end of the helix. Accession numbers are underlined.

\begin{tabular}{|c|c|c|c|c|c|c|}
\hline Taxon & H15 & H17 & $\mathbf{H} 21$ & H22-23 & H41 & H44 \\
\hline \multicolumn{7}{|l|}{$\begin{array}{l}\text { Nostochophycidae } \\
\text { Nostocaceae }\end{array}$} \\
\hline Anabaena cf. cylindrica XP6B AJ630414 & $1_{1}$ & $1_{3}$ & $1_{28}$ & $1_{30}$ & $2{ }_{3}$ & - \\
\hline Anabaenopsis sp. PCC9215 $\underline{\mathrm{AY} 038033}$ & $1_{1}$ & $1_{3}$ & $1{ }_{3}$ & $1_{28}$ & $1_{18}$ & $5_{6}$ \\
\hline Aphanizomenon flos-aquae PCC7905 $\underline{\mathrm{AY} 038035}$ & $1_{1}$ & $1_{5}$ & $1_{14}$ & $1_{28}$ & $1_{19}$ & $3_{2}$ \\
\hline Cuspidothrix issatschenkoi Otu37s7 AJ630446 & $1_{1}$ & $1_{3}$ & $1{ }_{1}$ & $2_{4}$ & $1_{20}$ & $2_{8}$ \\
\hline Cylindrospermum stagnale $\mathrm{PCC} 7417 \underline{\mathrm{AJ} 133163}$ & $1_{1}$ & $1_{3}$ & $1_{14}$ & $1_{4}$ & $1_{22}$ & $4_{1}$ \\
\hline Desmonostoc muscorum II $\underline{\mathrm{AJ} 630452}$ & $1_{1}$ & $1_{1}$ & $1_{4}^{\circ}$ & 2,3 & $2{ }_{2}$ & 23 \\
\hline Dolichospermum lemmermannii $\mathrm{AJ} 630424$ & $1_{1}$ & $1_{3}$ & $1_{13}$ & $1_{26}$ & $1_{16}$ & $2{ }_{7}$ \\
\hline Dolichospermum planktonica $\underline{\mathrm{AY} 702218}$ & $1_{1}$ & $1_{3}$ & $1_{14}$ & $1_{25}$ & $1_{17}$ & - \\
\hline Mojavia pulchra JT2-VF2 AY577534 & $1_{1}$ & $1_{3}$ & $1_{25}$ & $1_{18}$ & $2{ }_{2}$ & $1_{5}$ \\
\hline Nodularia harveyana BECID29 AJ781146 & $1_{1}$ & $1_{3}$ & $1{ }_{2}$ & $1_{7}$ & $1_{21}$ & - \\
\hline Nostoc commune NC3 EU586722 & $1_{1}$ & $1_{1}$ & $1_{1}$ & $1_{1}$ & $1_{1}$ & $1_{1}$ \\
\hline Nostoc commune NC1-M2 EU586725 & $1_{2}$ & $1_{1}$ & $1_{33}$ & $1_{41}$ & $1_{41}$ & $1_{6}$ \\
\hline Nostoc commune HHCP EU586724 & $1_{1}$ & $1_{1}$ & $4_{1}$ & $1_{2}$ & $1_{6}$ & $2_{2}$ \\
\hline Nostoc commune WY1KK1 EU586733 & 2 & $1_{2}$ & $1_{4}$ & $1_{17}$ & $1_{8}$ & $5_{2}$ \\
\hline Nostoc desertorum CM1-VF14 $\underline{\text { AY } 579901}$ & $1_{1}$ & $1_{1}$ & $3_{1}$ & $1_{15}$ & $1_{2}$ & $1_{1}$ \\
\hline Nostoc piscinale CENA21 $\underline{\mathrm{AY} 218832}$ & $1_{1}$ & $3_{1}$ & $1_{2}$ & $1_{16}$ & $1_{4}$ & - \\
\hline Nostoc punctiforme NC6 EU586731 & $1_{1}$ & $2_{1}$ & $1_{3}$ & $1_{3}$ & $1_{7}$ & 23 \\
\hline Spherospermopsis kisseleviana $\underline{\mathrm{AY} 701557}$ & $1_{1}$ & $2{ }_{1}$ & $1_{3}$ & $1_{32}$ & $1_{7}$ & - \\
\hline Trichormus sp. PCC7120 $\underline{\mathrm{AF} 317631}$ & $1_{1}$ & $8_{1}$ & $1_{12}$ & $1_{24}$ & $1_{42}$ & $2{ }_{1}$ \\
\hline Trichormus azollae BAI1983 AJ630454 & $1_{1}$ & $1_{4}$ & $1_{24}$ & $1_{19}$ & $1_{1}$ & $2{ }_{4}$ \\
\hline Trichormus doliolum $1 \underline{\mathrm{AJ} 630455}$ & $1_{1}$ & $1_{4}$ & $1_{6}$ & $1_{4}$ & $1_{9}$ & $2_{5}$ \\
\hline Trichormus variabilis Hindák 2001/4 AJ630456 & $1_{1}$ & $1_{3}$ & $1_{7}$ & $1_{4}$ & $1_{10}$ & $2_{6}$ \\
\hline \multicolumn{7}{|l|}{ Microchaetaceae } \\
\hline Coleodesmium wrangelii $114-2 \mathrm{~B}$ AF 334702 & $1_{1}$ & $3_{3}$ & $1_{9}$ & $1_{5}$ & $1_{44}$ & 27 \\
\hline Rexia erecta CAT1M $\underline{\mathrm{AY} 452533}$ & $1_{1}$ & $5_{1}$ & $1_{10}$ & $1_{21}$ & $2{ }_{1}$ & - \\
\hline Spirirestis rafaelensis SRS6 $\underline{\mathrm{AF} 334692}$ & $1_{1}$ & $2{ }_{3}$ & $1_{8}$ & $1_{20}$ & $1_{43}$ & $5_{2}$ \\
\hline \multicolumn{7}{|l|}{ Fischerellaceae } \\
\hline Chlorogloeopsis fritschii $\mathrm{PCC} 6718 \underline{\mathrm{AF} 132777}$ & $1_{1}$ & $3_{2}$ & $1_{11}$ & $1_{19}$ & $1_{45}$ & $5_{3}$ \\
\hline Fischerella major NIES-592 $\underline{\mathrm{AB} 093487}$ & $1_{1}$ & $4_{1}$ & $1^{\circ}$ & $1_{23}$ & $1_{12}$ & $5_{1}$ \\
\hline Fischerella muscicola SAG 1427-I $\underline{\mathrm{AB} 075985}$ & $1_{1}$ & $3_{9}$ & $1{ }_{5}$ & $1_{23}$ & $1_{14}$ & 8 \\
\hline Fischerella muscicola PCC $7414 \underline{\mathrm{AF} 132788}$ & $1_{1}$ & $4_{4}$ & $1^{\prime}{ }_{2}$ & 2, & $1_{15}$ & 8 \\
\hline Hapalosiphon welwitschii $\underline{\mathrm{AY} 034793}$ & $1_{1}$ & $6_{1}$ & $1_{3}^{\prime}$ & $1_{23}$ & $1_{14}$ & $5_{4}$ \\
\hline Mastigocladus indica CALU $987 \underline{\text { EU116033 }}$ & $1_{1}$ & $1_{7}$ & $1_{29}$ & $1_{6}$ & $1_{46}$ & - \\
\hline Mastigocladus laminosus KOV1987 EU11603 & $1_{1}$ & $4_{1}$ & $1^{\prime}{ }_{1}$ & $1_{22}$ & $1_{11}$ & - \\
\hline
\end{tabular}


Table 2 Cont.

\begin{tabular}{|c|c|c|c|c|c|c|}
\hline Mastigocladus laminosus SAG484 EU116035 & $1_{1}$ & $6_{1}$ & $1^{\prime}{ }_{2}$ & $2_{2}$ & $1_{12}$ & - \\
\hline Westiellopsis prolifica SAG16.93 $\underline{\text { AJ544086 }}$ & $1_{1}$ & $6_{2}$ & $1_{3}^{\prime}$ & $1_{23}$ & $1_{13}$ & - \\
\hline \multicolumn{7}{|l|}{ Oscillatoriophycidae } \\
\hline Microcoleus acremanii UTCC $313 \underline{\mathrm{AF} 218369}$ & $1_{1}$ & $1_{6}$ & $1_{15}$ & $1_{35}$ & $4_{1}$ & - \\
\hline Microcoleus autumnalis Arct-Ph5 $\underline{\mathrm{DQ} 493873}$ & $1_{1}$ & $3_{8}$ & $1_{27}$ & $1_{33}$ & $4_{1}$ & $6_{1}$ \\
\hline Microcoleus vaginatus $\mathrm{CSVMC1} \underline{\mathrm{AF} 355355}$ & $1_{1}$ & $9_{1}$ & $1_{15}$ & $1_{35}$ & $4_{2}$ & - \\
\hline Microcoleus vaginatus $\mathrm{MOA} 4 \mathrm{MC} 3-3 \underline{\mathrm{AF} 355358}$ & $1_{1}$ & $9_{1}$ & $1_{15}$ & $1_{36}$ & $4_{2}$ & - \\
\hline Microcoleus vaginatus $\mathrm{PCC} 9802 \underline{\mathrm{AF} 284803}$ & $1_{1}$ & $9_{1}$ & $1_{26}$ & $3_{2}$ & $4_{1}$ & $5_{5}$ \\
\hline Microcoleus vaginatus $\mathrm{SEV} 2 \mathrm{MC} 1 \underline{\mathrm{AF} 355362}$ & $1_{3}$ & $9_{2}$ & $2{ }_{1}$ & $1_{35}$ & $4_{1}$ & - \\
\hline Microcoleus vaginatus USPCI-6B EU586737 & $1_{4}$ & $9_{3}$ & $2{ }_{1}$ & $1_{35}$ & $4_{1}$ & - \\
\hline Planktothrix rubescens NIVA-CYA1 B045926.1 & $3_{1}$ & $3_{4}$ & $1_{20}$ & $1_{38}$ & $3_{2}$ & - \\
\hline Microcoleus steenstrupii CSV2-1A $\underline{\mathrm{AF} 355383}$ & $1_{1}$ & $1_{5}$ & $1_{31}$ & $1_{36}$ & $1_{28}$ & - \\
\hline \multicolumn{7}{|l|}{ Synechoccophycidae } \\
\hline Cyanobium sp. JJ21H3 $\underline{\mathrm{AM} 710375}$ & $1_{5}$ & $3_{7}$ & $1_{32}$ & $3_{3}$ & $3_{3}$ & $7_{3}$ \\
\hline Cyanobium sp. JJ23-1 $\underline{\mathrm{AM} 710376}$ & $1_{5}$ & $3_{7}$ & $2{ }_{1}$ & $3_{3}$ & $3_{3}$ & $7_{4}$ \\
\hline Cyanobium sp. JJ22K $\underline{\text { AM710342 }}$ & $1_{1}$ & $4_{4}$ & $2_{5}$ & $3_{3}$ & $1_{39}$ & $7_{3}$ \\
\hline Geitlerinema sp. MBIC10006 $\underline{\mathrm{AB} 058204}$ & $1_{1}$ & $3_{5}$ & $1_{21}$ & $1_{34}$ & $2_{4}$ & - \\
\hline Leptolyngbya appalachiana EF429286 & $1_{5}$ & $4_{1}$ & $5_{1}$ & $1_{37}$ & $3_{1}$ & $8_{1}$ \\
\hline Leptolyngbya boryana UTEX $485 \underline{\mathrm{AF} 132793}$ & $1_{1}$ & $5_{1}$ & $1_{17}$ & $2_{5}$ & $1_{23}$ & $7_{1}$ \\
\hline Leptolyngbya tenerrima UTCC $77 \underline{\mathrm{AF} 218368}$ & $1_{1}$ & $5_{1}$ & $1_{17}$ & $2_{5}$ & $1_{23}$ & $7_{1}$ \\
\hline Leptolyngbya sp. SEV4-3-c2 AY239597 & $1_{5}$ & $5_{1}$ & $1_{18}$ & $2_{4}$ & $1_{1}$ & - \\
\hline Limnothrix redekei NIVA-CYA 227/1 $\underline{\text { AB045929 }}$ & $1_{1}$ & 8 & $1_{23}$ & $1_{36}$ & $1_{25}$ & $4_{2}$ \\
\hline Spirulina sp. PCC6313 X75045 & $3_{1}$ & $8_{2}$ & $1_{19}$ & $3_{1}$ & $1_{46}$ & $7_{2}$ \\
\hline Trichocoleus desertorum JO2-1B EU586743 & $1_{1}$ & $1_{7}$ & $1_{30}$ & $1_{33}$ & $1_{27}$ & - \\
\hline \multicolumn{7}{|l|}{ Gloeobacterophycidae } \\
\hline Gloeobacter violaceus $\mathrm{PCC} 7421 \underline{\mathrm{AF} 132790}$ & $1_{1}$ & $7_{1}$ & $1_{22}$ & $1_{31}$ & $1_{26}$ & $7_{1}$ \\
\hline
\end{tabular}

to proof sequences using secondary structure. Mfold (ZUKER 2003) is a useful tool for initial identification of structure but only assumes canonical base-pairing. Secondary structure in helices can be preserved even with single nucleotide changes if non-canonical pairing occurs. Some non-canonical pairs form easily, such as G:U; however, in E. coli A:G, A:A, U:U, C:C, $\mathrm{G}: \mathrm{G}$, and $\mathrm{C}: \mathrm{A}$ also are known to form. Every helix examined in this study had at least one taxon with a non-canonical base pair belonging to this latter group, and most helices (H17, H21, H22-H23, H44) had such pairings in every taxon studied. In the absence of evidence from crystallography, it is difficult to know when secondary structure is preserved through formation of these unusual pairings. This uncertainty makes it more difficult to identify sequence problems that may be due to sequencing error. When two or more consecutive non-canonical base pairs are required to maintain a helix, we assume that the structure is not maintained, or that sequencing error exists.

Other analyses utilizing secondary structure could be tested. TIPPERY \& Les (2008) devised a coding scheme for phylogenetic analysis utilizing secondary structure of eukaryotic ITS1 and ITS2 sequences which allowed analysis independent of the sequence. The analysis based on coding of complimentarity produced results in good agreement with the maximum parsimony analy-sis of the same ITS data, and bootstrap support was improved (but topology did not change) when the data sets were included in a single analysis. It is difficult to know if the secondary structures of $16 \mathrm{~S}$ rRNA genes vary sufficiently to yield a similar signal to that detected using the ITS. Certainly the much longer sequence in the $16 \mathrm{~S}$ rRNA gene would 
mean the method would be considerably more labor intensive, but in future studies addressing particular phylogenetic questions the effort may be justified. Other alternatives to our approach and that of TIPPERY \& LES (2008) include down-weighting of paired sites in helices (Wheeler \& Honeycutt 1988; Steele et al. 1991; DiXON \& HiLLIS 1993) and linkage of paired sites in maximum likelihood analysis (KJER 2004).

In summary, this exercise has shown that secondary structure of the small subunit rRNA molecule in cyanobacteria is very similar to that seen in other prokaryotic taxa, such as E. coli. However, there are some notable differences within the variable helices as well as other helices, particularly with reference to unilateral and bilateral bulges. Some motifs seem to be unique to cyanobacteria and highly conserved within the phylum. The phylogenetic signal in the 16S rRNA secondary structure could inform analyses of evolutionary relationships and assist in detecting sequencing error. As the number of sequences available in public databases grows, we suspect that greater care with respect to choosing sequences, as well as incorporating weightings for variable and nonvariable regions, will increase our ability to derive more stable (and preferably) more accurate phylogenetic hypotheses in cyanobacteria and other bacterial taxa. We suspect that the immediate benefit to be derived from analysis of secondary structure of the 16S rRNA molecule is detection of sequence error in one's own sequences and more importantly in the sequences one is selecting from a large database for phylogenetic analysis. A future benefit will be in improved phylogenetic analysis when weightings based on secondary structure can be more artfully assigned than the simple approach used in this paper.

\section{ACKNOWLEDGEMENTS}

This work was completed with the aid of a travel grant to Klára Reháková from the Fulbright Program, Bureau of Educational and Cultural Affairs, U.S. Department of State to visit John Carroll University. Supplies and sequencing expenses were provided by internal funds form John Carroll University to Jeff Johansen and Mike Martin.

\section{REFERENCES}

BohunickÁ, M.; Johansen, J.R. \& FučíkovÁ, K. (2011): Tapinothrix clintonii sp. nov. (Pseudanabaenaceae, Cyanobacteria), a new species at the nexus of five genera. - Fottea 11: 127-140.

Boyer, S.L.; Johansen J.R. \& Flechtner V.R. (2002): Characterization of the $16 \mathrm{~S}$ rRNA gene and associated 16S-23S ITS region in Microcoleus: evidence for the presence of cryptic species in desert soils. - J. Phycol. 38:1222-35.

Brosius, J.; Palmer, M.L.; Kennedy, P.J. \& Noller, H.F. (1978): Complete nucleotide sequence of a 16S ribosomal RNA gene from Escherichia coli. - Proc.
Natl. Acad. Sci. USA 75:4801-4805.

Cannone, J.J.; Subramanian S.; Schnare M.N.; Collett J. R.; D'Souza, L.M.; Du Y.; Feng B.; Lin N.; Madabusi L.V.; Müller K.M.; Pande N.; Shang Z.; Yu N. \& GUTELL R.R. (2002): The comparative RNA web (CRW) site: an online database of comparative sequence and structure information for ribosomal, intron, and other RNAs. - BMC Bioinformatics 3:15.

Carbon, P.; Ehresmann, C.; Ehresmann, B. \& Ebel, J. P. (1979): The complete nucleotide sequence of the ribosomal 16-S RNA from Escherichia coli. Experimental details and cistron heterogeneities. Eur. J. Biochem. 100:399-410.

Casamatta, D.A.; Gomez, S.R. \& Johansen, J.R.. (2006): Rexia erecta gen. et sp. nov. and Capsosira lowei sp. nov., two newly described cyanobacterial taxa from the Great Smoky Mountain National Park (USA). Hydrobiologia 561:13-26.

Castenholz, R.W. (2001): Oxygenic photosynthetic bacteria. - In: Boone, D.R. \& CASTENHOLZ, R.W. (eds): Bergey's Manual of Systematic Bacteriology (2nd Edition). - pp. 473-600, Springer-Verlag, New York.

Dixon, M.T. \& Hillis, D.M. (1993): Ribosomal RNA secondary structure: compensatory mutations and implications for phylogenetic analysis. - Mol. Biol. Evol. 10: 256-267.

Elgavish, T.; Cannone, J. J.; Lee, J. C.; Harvey, S. C. \& Gutell, R. R. (2001): AA.AG@helix.ends: A:A and A:G base-pairs at the ends of $16 \mathrm{~S}$ and 23S rRNA helices. - J. Mol. Biol. 310:735-53.

Ewing, B.; Hillier, L.; Wendl, M.C. \& Green, P. (1998): Base-calling of automated sequencer traces using phred. I. Accuracy assessment. - Genome Res. $8: 175-185$.

Ewing, B. \& Green, P. (1998): Base-calling of automated sequencer traces using phred. II. Error probabilities. - Genome Res. 8:186-194.

Flechtner, V. R.; Boyer S. L. \& Johansen J. R. (2002): Spirirestis rafaelensis gen. etsp. nov. (Cyanophyceae), a new cyanobacterial genus from arid soils. - Nova Hedwigia 74:1-24.

Fox, G.W. \& Woese, C.R. (1975): 5S RNA secondary structure. - Nature 256: 505-507.

Garcia-Pichel, F.; López-Cortés, A. \& Nübel, U. (2001): Phylogenetic and morphological diversity of cyanobacteria in soil desert crusts from the Colorado Plateau. - Appl. Environ. Microbiol. 67:1902-1910.

Goertzen, L.R.; Cannone, J.J.; Gutell, R.R. \& Jansen, R.K. (2003): ITS secondary structure derived from comparative analysis: implications for sequence alignment and phylogeny of the Asteraceae. - Mol. Phylogenet. Evol. 29: 216-234.

Goertzen, L.R. \& Theriot, E.C. (2003): Effect of taxon sampling, character weighting, and combined data on the interpretation of relationships among the heterokont algae. - J. Phycol. 39:423-439.

Gottschling, M.; Hilger, H.H.; Wolf, M. \& Diane, N. (2001): Secondary structure of the ITS1 transcript and its application in a reconstruction of the phylogeny of Boraginales. - Plant Biol. 3: 629-636.

Gutell, R. R.; Larsen, N. \& Woese, C. R. (1994): Lessons from an evolving rRNA: 16S and 23S rRNA structures from a comparative perspective. - Microbiol. Rev. 58:10-26. 
Gutell, R.R.; Cannone, J.J.; Shang, Z.; Du, Y. \& Serra, M.J. (2000): A story: unpaired adenosine bases in ribosomal RNAs. - J. Mol. Biol. 304: 335-354.

Gutell, R.R.; Lee, J.C. \& CAnnone, J.J. (2002): The accuracy of ribosomal RNA comparative structure models. - Curr. Opinion Struct. Biol. 12: 301-10.

HaŠLer, P.; DVořÁK, P.; Johansen, J.R.; Kitner, M.; OndŘEJ, V. \& PoulíčKovÁ, A. (2012): Morphological and molecular study of epipelic filamentous genera Phormidium, Microcoleus and Geitlerinema (Oscillatoriales, Cyanophyta/Cyanobacteria). Fottea 12: 341-356.

HAŠLER, P.; DVoŘÁK, P. \& PoulíčKovÁ, A. (2014): Anew genus of filamentous epipelic cyanobacteria, Johansenia Preslia 86: 81-94.

Hoffmann, L.; KomÁReK, J. \& KaštovskÝ, J. (2005): System of cyanoprokaryotes (cyanobacteria) - state in 2004. - Algological Studies 117: 95-115.

Johansen, J.R.; Olsen, C.E.; Lowe, R.L.; Fučíková, K. \& Casamatta, D.A. (2008): Leptolyngbya species from selected seep walls in the Great Smoky Mountains National Park. - Algological Studies 126: 21-36.

Johansen, J.R.; BohunickÁ, M.; LukeŠOvÁ, A.; HrČKovÁ, K.; Vaccarino, M.A. \& Chesarino, N.M. (2014): Morphological and molecular characterization within 26 strains of the genus Cylindrospermum (Nostocaceae, Cyanobacteria), with descriptions of three new species. - J. Phycol. 50: 187-202.

KJER, K.M. (1995): Use of rRNA secondary structure in phylogenetic studies toidentifyhomologous positions: an example of alignment and data presentation from the frogs. - Mol. Phylogenet. Evol. 4: 314-330.

KJER, K.M. (2004): Aligned 18S and insect phylogeny. Syst. Biol. 53: 506-514.

KomÁreK, J. \& Anagnostidis, K. (1998): Cyanoprokaryota 1. Chroococcales. - In: EtTl, H.; GärTnER, G.; HeYNIG, H. \& Mollenhauer, D. (eds): Süßwasserflora von Mitteleuropa 19/1. - 548 pp., Gustav Fischer, Stuttgart - Jena.

KomÁreK, J. \& Anagnostidis, K. (2005): Cyanoprokaryota 2. Oscillatoriales. - In: BÜDEL, B.; GärtnER, G.; Krienitz, L. \& Schaerl, M. (eds): Süßwasserflora von Mitteleuropa 19/2. - 759 pp., Gustav Fischer, Stuttgart - Jena.

KomÁreK, J. (2013): Cyanoprokaryota 3. Nostocales. - In: Büdel, B.; GÄrtner, G.; Krienitz, L. \& Schaerl, M. (eds): Süßwasserflora von Mitteleuropa 19/3. - 1130 pp., Gustav Fischer, Stuttgart - Jena, Germany.

LukešovÁ, A.; Johansen, J.R.; Martin, M.P. \& Casamatta, D.A. (2009): Aulosira bohemensis sp. nov.: further phylogenetic uncertainty at the base of the Nostocales (Cyanobacteria). - Phycologia 48:118-129.

Meares, J. A.; Cannone, J. J.; Stagg, S. M.; Gutell, R. R.; Agrawal, R. K. \& Harvey, S. C. (2002): Modeling a minimal ribosome based on comparative sequence analysis. - J. Mol. Biol. 321:215-234.

Mühlsteinová, R.; Johansen, J.R.; Pietrasiak, N. \& Martin, M.P. (2014a): Polyphasic characterization of Kastov skya adunca gen. nov. et comb. nov. (Oscillatoriales, Cyanobacteria) from desert soils of the Atacama Desert, Chile. - Phytotaxa 163: 216-228.

Mühlsteinová, R.; Johansen, J.R.; Pietrasiak, N.; Martin, M.P.; Osorio-SAntos, K. \& Warren, S.D. (2014b): Polyphasic characterization of Trichocoleus desertorum sp. nov. (Pseudanabaenales,
Cyanobacteria) from desert soils and phylogenetic placement of the genus Trichocoleus. - Phytotaxa 163: 241-261.

Nübel, U.; Garcia-Pichel, F. \& Muyzer, G. (1997): PCR primers to amplify 16S rRNA genes from cyanobacteria. - Appl. Env. Microbiol. 63:3327-32.

Osorio-Santos, K.; Pietrasiak, N.; Bohunická, M.; Miscoe, L.H.; Kovacik, L.; Martin, M.P. \& Johansen, J.R. (2014): Seven new species of Oculatella (Pseudanabaenales, Cyanobacteria). - Euro. J. Phycol. 49: (accepted).

Perkerson, R.; Johansen, J.R.; KovaciK, L.; Brand, J. \& Casamatta, D.A. (2011): A unique Pseudanbaenalean (Cyanobacteria) genus Nodosilinea gen. nov. based on morphological and molecular data. - J. Phycol. 47: 1397-1412.

Powers, T. \& Noller, H.F. (1995): Hydroxyl radical footprinting of ribosomal proteins on 16S rRNA. RNA 1:194-209.

Řeháková, K.; Johansen, J.R.; Casamatta, D.A.; Xuesong L. \& VinCENT J. (2007): Morphological and molecular characterization of selected desert soil cyanobacteria: Three species new to science including Mojavia pulchra gen. et sp. nov. - Phycologia 46: 481-502.

Segiesmund, M.A.; Johansen, J.R.; Karsten, U. \& Friedl, T. (2008): Coleofasciculus gen. nov. (Cyanobacteria): morphological and molecular criteria for revision of the genus Microcoleus Gomont. - J. Phycol.44:15721585.

ShiH, P.M.; Wu, D.; Latifi, A.; Axen, S.D.; Fewer, D.P.; Talla, E.; Calteau, A.; Cai, F.; Tandeau de Marsac, N.; RipPKa, R.; Herdman, M.; Sivonen, K.; Coursin, T.; LAURENT, T.; GoOdWIn, L.; Nolan, M.; DAVENPORT, K.W.; Han, C.S.; Rubin, E.M.; EISEnA, J.A.; Woyke, T.; Gugger, M., \& Kerfeld, C.A. (2013): Improving the coverage of the cyanobacterial phylum using diversity-driven genome sequencing. - PNAS 110: 1053-1058.

Smit, S.; Widmann J. \& KNIGHT R. (2007): Evolutionary rates vary among rRNA structural elements. - Nucleic Acids Res. 35:3339-54.

SMith, S.D. \& Bond, J.E. (2003): An analysis of the secondary structure of the mitochondrial large subunit rRNA gene (16S) in spiders and its implications for phylogenetic reconstruction. - J. Arachnol. 31:4454.

Steele, K.P.; Holsinger, K.E.; Jansen, R.K. \& TAYlor, D.W. (1991): Assessing the reliability of 5S rRNA sequence data for phylogenetic analysis in green plants. - Mol. Biol. Evol. 8: 240-248.

Strunecký, O.; Komárek, J.; Johansen, J.R.; Lukešová, A. \& Elster. J. (2013): Molecular and morphological criteria for revision of the genus Microcoleus.- J. Phycol. 49: 1167-1180.

Swofford, D.L. (1998): PAUP*. Phylogentic analysis of parsimony ("and other methods). Version 4 - Sinauer Associates, Sunderland, MA.

Thompson, J. D.; Higgins D.G. \& Gibson T.J. (1994): CLUSTALW: improving the sensitivity of progressive multiple sequence alignments through sequence weighting, position-specific gap penalties and weight matrix choice. - Nucleic Acids Res. 22:4673-80.

TipPery, N.P. \& Les, D.H. (2008): Phylogenetic analysis of the internal transcribed spacer (ITS) region in 
Menyanthaceae using predicted secondary structure. - Mol. Phylogenet. Evol. 49: 526-537.

TURNer, S. (1997): Molecular systematics of oxygenic photosynthetic bacteria. - Plant Syst. Evol., Suppl. 11:13-52.

Vaccarino, M.A. \& Johansen, J.R. (2011): Scytonematopsis contorta sp. nov. (Nostocales), a new species from the Hawaiian Islands. - Fottea 11: 149-161.

Wheeler, W.C. \& Honeycutt, R.L. (1988): Paired sequence difference in ribosomal RNAs: evolutionary and phylogenetic implications. - Mol. Biol. Evol. 5: 90-96.

Wilde, S.B.; Murphy, T.M.; Hope, C.P.; Habrun, S.K.;
Kempton, J.; Birrenkott, A.; Wiley, F.; Bowerman, W.W. \& Lewitus, A.J. (2005): Avian Vacuolar Myelinopathy linked to exotic aquatic plants and a novel cyanobacterial species. - Environ. Toxicol. 20: 348-353.

Wilmotte, A.; Van der Auwera, C. \& De Wachter, R. (1993): Structure of the 16S ribosomal RNA of the thermophilic cyanobacteria Chlorogloeopsis HTF (Mastigocladus laminosus HTF) strain PCC 7518 and phylogenetic analysis. - FEBS Lett. 317:96-100.

ZuKer, M. (2003): Mfold web server for nucleic acid folding and hybridization prediction. - Nucleic Acids Res. 31:3406-3415.

(C) Czech Phycological Society (2014)

Received March 24, 2014

Accepted May 24, 2014 